\title{
Justification of Expediency of Studying Transport Mobility of the Population on the Basis of Monitoring of Subscribers Mobile Communication
}

\author{
Igor M. Blyankinshtein*, \\ Alexander I. Fadeev, Andrey V. Fedorov, \\ Nikolay V. Shadrin and Elena G. Makhova \\ Siberian Federal University \\ 79 Svobodny, Krasnoyarsk, 660041, Russia
}

Received 15.11.2014, received in revised form 25.01.2015, accepted 21.02.2015

The feasibility of studying the transport mobility of the population based on the monitoring of mobile subscribers was proved. Technical, legal, statistical, organizational and economic aspects of the implementation of this area in terms of the Russian Federation, as well as experience in implementation of this trend abroad were considered. Development of methods, technologies and software system for the study of mobility of the population in the city will optimize the development of the road and route network of passenger transport in the city of Krasnoyarsk and the Krasnoyarsk Territory.

Keywords: movements of users of mobile phones, transport mobility of the population, monitoring of subscribers of communication.

\section{Обоснование целесообразности изучения}

\author{
транспортной подвижности населения
}

\section{на основе мониторинга абонентов мобильной связи}

И.М. Блянкинштейн, А.И. Фадеев, А.В. Фёдоров, Н.В. Шадрин, Е.Г. Махова

Сибирский федеральный университет Россия, 660041, Красноярск, пр. Свободньй, 79

Обосновывается ичелесообразность изучения транспортной подвижности населения на основе мониторинга абонентов мобильной связи. Рассмотрень технический, юридический, статистический, организационный и экономические аспекты реализации данного направления в условиях Российской Федерации, а также опыт реализации этого направления за рубежом. Разработка методики, технологии и программного комплекса для изучения перемещения

(c) Siberian Federal University. All rights reserved

* Corresponding author E-mail address: blyankinshtein@mail.ru 
населения в мегаполисе позволит оптимизировать улично-дорожную и марирутную сети пассажирского транспорта на территориях г. Красноярска и Красноярского края.

Ключевые слова: перемещения пользователей мобильных телефонов, транспортная подвижность населения, мониторинг абонентов связи.

\section{Введение}

Изучение закономерностей транспортной подвижности населения в мегаполисах является ключевым вопросом для развития улично-дорожной сети, разработки и оптимизации маршрутов пассажирского транспорта. Названная проблема особенно актуальна для Красноярска, миллионного сибирского города, краевого центра, в котором состояние и развитие уличнодорожной сети значительно отстает от потребностей автомобилизации, а уровень качества обслуживания пассажиров общественным транспортом недостаточно высок. Необходимость решения данной проблемы для Красноярска в ближнесрочной перспективе обусловлена тем, что в 2019 году в городе будет проводиться XXIX Всемирная зимняя универсиада, уровень транспортного обслуживания которой будет существенно влиять на формирование международного имиджа Красноярска и Сибирского региона в целом.

Теория и практика изучения подвижности населения располагают множеством методов исследования пассажиропотоков [1]:

- Натурные исследования реализуются талонными, табличными, визуальными, силуэтными и опросными методами с привлечением большого количества людей (учетчиков и контролеров).

- Анкетный метод предполагает опрос населения или заполнение анкет о характере и направлениях регулярных поездок. Наибольший эффект анкетное обследование дает при опросе населения по месту работы основных пассажирообразующих и пассажиропоглощающих пунктов обслуживаемого района, хотя оно может проводиться и непосредственно в подвижном составе или на остановочных пунктах.

- Отчетно-статистический метод обследования опирается на данные билетноучетных листов, количество проданных билетов. Помимо проданных билетов необходимо учитывать число лиц, перевезенных по месячным проездным билетам, служебным удостоверениям, и лиц, пользующихся правом бесплатного льготного проезда, а также не приобретших билет.

- Автоматизированные методы обеспечивают получение информации с использованием технических средств при ограниченном участии людей. К ним относятся контактные, неконтактные, косвенные и комбинированные методы.

Все названные методы изучения характеризуются значительными время- и трудозатратами при сборе, обработке и анализе данных.

Цель данной статьи - обосновать целесообразность решения данной проблемы с использованием современных информационных технологий, а именно на основе мониторинга географических координат абонентов мобильной сотовой связи. Технология решения данной проблемы базируется на алгоритмах решения навигационных задач, в публикациях $[2,3]$ отмечается ее инновационный характер, актуальность для сферы пассажирского транспорта и сложность практической реализации. В этом контексте необходимо рассмотреть технический, юридиче- 
ский, статистический, организационный и экономический аспекты решения проблемы, а также зарубежный опыт.

\section{Технический аспект реализации}

Техническая возможность решения поставленной задачи, на наш взгляд, имеется. Вопервых, сегодня оснащенность населения мобильными телефонами близка к 100 \%. Этот вопрос, конечно же, требует дополнительного исследования, так как современные мобильные телефоны позволяют параллельно пользоваться услугами нескольких операторов. Поэтому, проведя исследование репрезентативной выборки абонентов, можно получить количественные оценки данного параметра - степени охвата населения мобильной связью вообще с учетом распределения абонентов по операторам связи в регионе, а также доли дублирования операторов.

Во-вторых, в составе опций всех основных операторов сотовой связи уже имеются специализированные функции по определению местоположения абонентов. В качестве примера рассмотрим функцию «Локатор» от МТС [4]. Эта услуга помогает определять, где находятся абоненты-друзья по данным о местоположении их телефонов в сетях «МТС», «Мегафон», «Билайн». Услуга «Локатор» работает на любом мобильном телефоне и не требует специальной настройки. Местоположение их телефонов в сетях «МТС», «Мегафон», «Билайн» определяется при регистрации в сети и не требует наличия GPRS-соединения. Пользоваться услугой можно с помощью SMS-команд, через веб-сайт или мобильное приложение. Чтобы определять местоположение вашего друга - абонента «МТС», «Мегафон» или «Билайн», вам надо сначала добавить его в ваш список друзей и получить его разрешение на определение местоположения (рис. 1), а затем обратиться к поисковому сервису услуги «Локатор».

В поисковом сервисе услуги предусмотрено ведение протокола, содержание которого и режим (интервал) контроля задаются посредством интерфейса, а именно: дата запроса, дата местоположения, имя абонента, статус запроса, местоположение и пр. (рис. 2). Данная услуга платная. В составе услуги «Локатор» имеются встроенные функции «Сотрудники», «Транспорт», «Координатор», которые в зависимости от решаемых задач позволяют определять местоположение групп абонентов в городе с точностью от 100 до 300 м, а в случае встроенных в смартфон приемников GPS/ГЛОНАCC - 3-5 м.

Подобный сервис имеется и в услуге «Радар», предоставляемой оператором сотовой связи «МегаФон» [5]. Услуга позволяет запрашивать координаты абонентов «МегаФона», МТС и «Билайна» на территории покрытия сети «МегаФон». Определить местоположение абонента можно только с его согласия, которое необходимо получить один раз. В зависимости от режима и степени использования в данной услуге предусмотрены как бесплатные варианты, так и платные. Варьируются количество контролируемых абонентов (в услуге «Радар» - до 5 абонентов, а в услуге «Навигатор» от «МегаФон» - до 10 абонентов), частота запросов местоположения и пр. Подобные сервисы имеются в арсенале и других операторов связи.

Таким образом, современный технический уровень развития мобильной связи обеспечивает возможность определения местоположения абонентов и, следовательно, может позволить решить на этой основе проблему изучения транспортной подвижности населения в мегаполисах. Необходимо отметить, что в исходном виде рассмотренные услуги операторов связи не адаптированы к анализу местоположения значительных групп населения (репрезентативных 


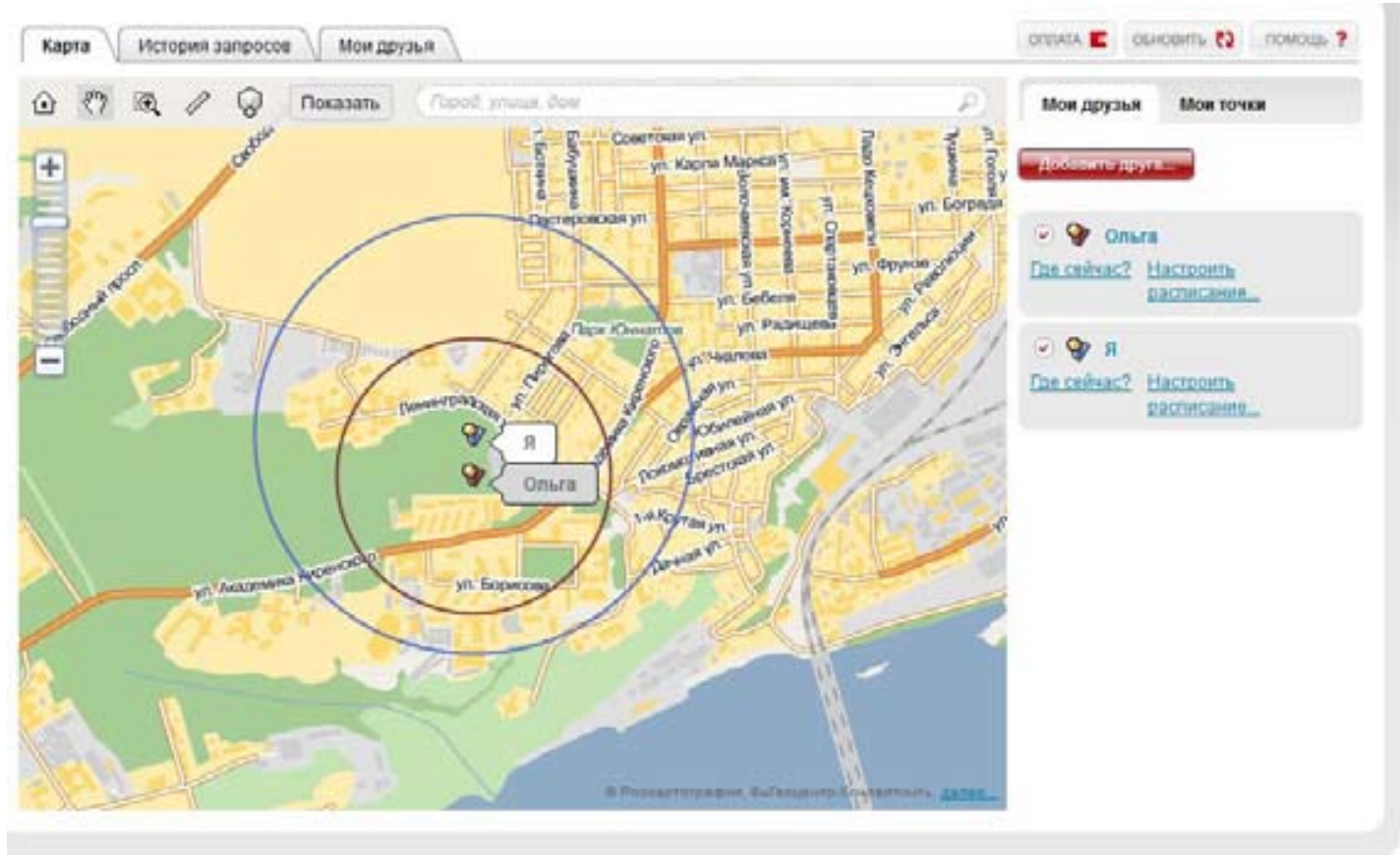

Рис. 1. Визуализация местоположения абонентов на карте региона

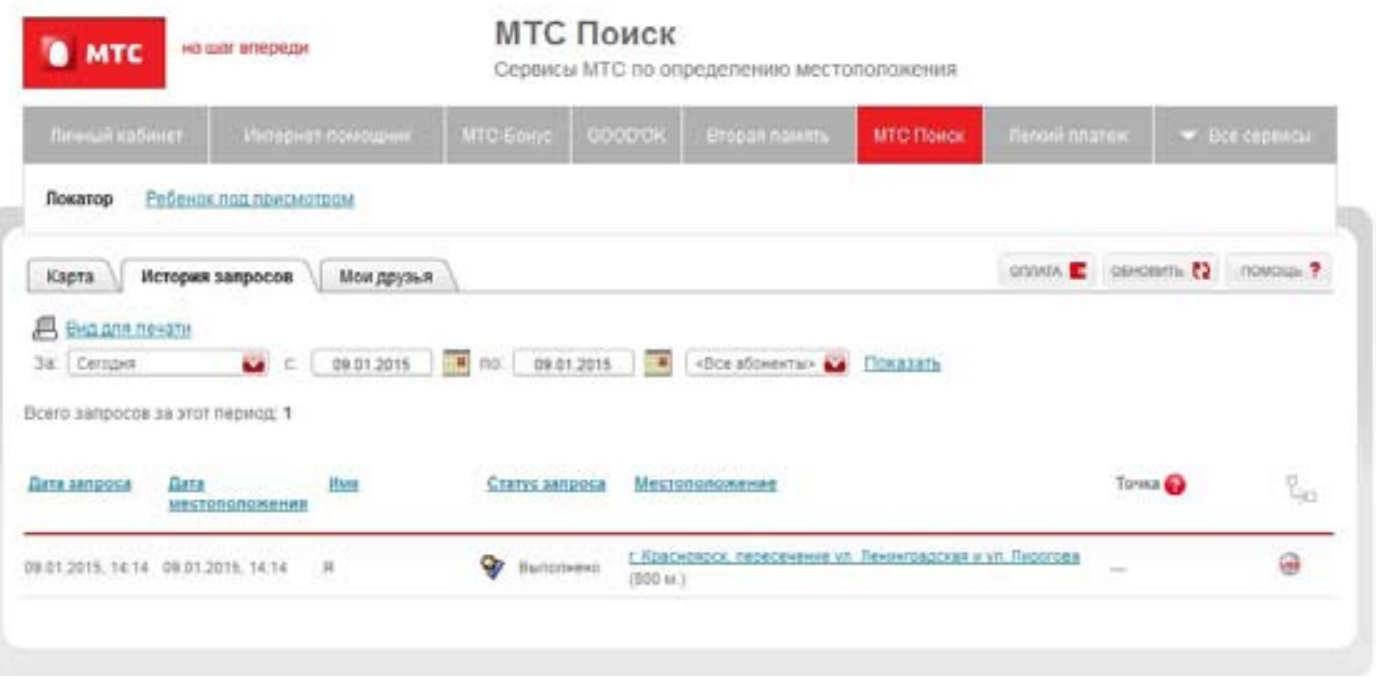

Рис. 2. Вид интерфейса и протокола услуги «Локатор» от МТС

выборок). Поэтому может понадобиться непосредственное участие операторов связи для адаптации сервисных функций к решению рассматриваемых задач.

\section{Юридический аспект реализации}

Сложность организации проведения исследования таким методом состоит в том, что некоторые аспекты передачи информации о местоположении абонента могут подпадать под 
действие Федерального закона «О связи» № 126-ФЗ от 07.07.2003 (ред. от 21.07.2014) а именно под п. 1-3 ст. 63 и п. 1 ст. 641, и ст. 7 Федерального закона «О персональных данных» № 152-Ф3 от 27.07.2006 (ред. от 21.07.2014)². Следовательно, информация о перемещении конкретного абонента, которой располагают операторы мобильной связи, конфиденциальна и может быть получена только с согласия абонента, либо такую информацию операторы связи могут предоставить только по запросу специальных (силовых) государственных органов (МВД, ФСБ и др.) [6].

Здесь просматриваются два возможных подхода к решению проблемы. Первый состоит в том, что с учетом особой актуальности рассматриваемой задачи (значимости ее влияния на функционирование, экономику и экологию города), технической специфики и планируемой технологии реализации данная проблема может быть решена путем обращения государственного органа к операторам связи с целью истребования у них информации о перемещениях масс абонентов, а также привлечения операторов связи к участию в таком исследовании. У операторов связи есть техническая и законодательно закрепленная возможность на основании ст. 63 Федерального закона «О персональных данных» № 152-Ф3 от 27.07.2006 [7] предоставить требуемую информацию о перемещениях групп абонентов с обезличиванием их персональных данных. Действительно, для решения данной задачи оператору не нужно раскрывать персональные данные абонентов. Со статистической точки зрения при изучении подвижности населения не важна конкретизация абонента, осуществляющего перемещение. Важен факт регистрации географических координат абонента мобильной связи и текущего времени. Следовательно, оператор сотовой связи, который будет участвовать в исследовании, должен будет создать некий профайл или массив данных, который позволит исследовательскому коллективу работать не с фактическими номерами абонентов сотовой связи, а с их условными номерами, присваиваемыми оператором по некоторому правилу.

Второй вариант состоит в том, что исследовательский коллектив создает некий информационный портал (сайт), на котором популярно излагается суть решаемой проблемы. С помощью СМИ (местное телевидение) данная идея «раскручивается», и жители города в добровольном порядке дают согласие на отслеживание своих координат на период проведения исследования, сообщая об этом на информационный портал.

Более предпочтительным для реализации видится первый вариант, так как большинство населения вряд ли осознает необходимость предоставления информации о собственных перемещениях, пусть и специализированному исследовательскому коллективу на ограниченный период времени. Кроме того, для реализации второго варианта может потребоваться значительно больше времени, пока не будет сформирована «добровольная» база данных по абонентам.

\section{Статистический аспект реализации}

Одним из важных вопросов для данного исследования является обоснование необходимой представительности исследуемой выборки абонентов мобильной связи. По данным официального сайта Территориального органа Федеральной службы государственной статистики по Красноярскому краю, на 1 января 2014 года общая численность населения в г. Красноярске составляла 1035528 чел., из них трудоспособного возраста 671350 чел.; среднесписочная чис- 
ленность работников организаций в г. Красноярске - 303138 чел. [8]. Если предположить, что объем репрезентативной выборки должен быть не менее $5 \%$ от генеральной совокупности, то в натуральном выражении это может составлять от 15 до 50 тыс. абонентов. А это весьма значительный объем обработки информации.

Другим важным вопросом является оценка необходимой и обеспечение достаточной точности регистрации координат абонентов в пространстве и времени. Все эти вопросы должны решаться на основе методов математической статистики и теории вероятностей. Кроме того, должна быть обеспечена возможность изменения состава выборки абонентов, варьирования ее объема, варьирования операторов сотовой связи и пр. То есть необходимо создать гибкий программный комплекс, который позволит получать данные о координатах обезличенных абонентов сотовой связи, аккумулировать их, обрабатывать, выявлять закономерности перемещения населения в пространстве и времени и анализировать их.

\section{Организационный аспект реализации}

Для решения названной проблемы необходимо создать специализированный исследовательский коллектив, включающий специалистов в сфере транспорта, обладающих высокой квалификацией в области информатики, программного обеспечения и математики. Такие специалисты в Красноярске есть: на факультете транспорта Политехнического института Сибирского федерального университета (ПИ СФУ) создана лаборатория транспортного моделирования. По данному научному направлению работают аспиранты кафедры «Транспорт» ПИ СФУ. С точки зрения усиления потенциала коллектива кафедры и созданной лаборатории, развития междисциплинарных связей возможна интеграция лаборатории транспортного моделирования с другими научными подразделениями СФУ, специализирующимися на применении информационных технологий, а также включение в ее состав специалистов - операторов сотовой связи, с которыми планируется взаимодействие.

Возможно также создание аналогичной специализированной структуры на более высоком административном уровне - на уровне городской или краевой администрации, а именно Центра мониторинга подвижности населения и транспортного поланирования, тем более что создание подобных центров предусматривается Транспортной стратегией ${ }^{4}$ России до 2030 года.

Как было отмечено, для решения обозначенной научно-технической проблемы необходимо, чтобы заинтересованные отраслевые структуры (Министерство транспорта Красноярского края) или другие государственные органы решили с операторами сотовой связи вопрос о доступе ограниченного исследовательского коллектива к данным о сигналах абонентов сотовой связи в обезличенной форме.

\section{Экономический аспект реализации}

Учитывая, что предлагаемые операторами связи услуги по определению координат местоположения абонентов платные, т. е. имеют для них определенный коммерческий интерес, можно предположить, что операторы связи примут участие в этом актуальном для города и всего Сибирского региона проекте и будут оказывать содействие в его реализации. Кроме того, уместно рассмотреть вопрос привлечения операторов к этой работе на другой основе - органы Федеральной службы безопасности имеют право 5 получать от операторов связи информацию,

$$
-259-
$$


необходимую для обеспечения безопасности проводимых на территории Российской Федерации массовых мероприятий, а именно к таким мероприятиям и относится запланированная в г. Красноярске XXIX Всемирная зимняя универсиада 2019 года.

Разработка методики, создание технологии и программного продукта для решения поставленной задачи изучения подвижности населения по перемещению абонентов мобильной связи потребуют определенных финансовых и трудовых затрат. Но, во-первых, эти затраты разовые. Во-вторых, они могут с лихвой окупиться за счет снижения совокупных затрат города в результате совершенствования улично-дорожной и маршрутной сети на основе полученных объективных данных. И, в-третьих, разработанный программный комплекс решения задачи может принести прибыль как самостоятельный коммерческий продукт. В любом случае разрабатываемая технология исследования и ее программная реализация должны быть конкурентоспособны в сравнении с существующими методами исследования подвижности населения.

\section{Зарубежный опыт}

Последние данные свидетельствуют об интенсивном развитии данного научнопрактического направления за рубежом $[9,10]$. Это обусловлено тем, что мобильные операторы в настоящее время вынуждены искать новые источники доходов, поэтому всё большее количество операторов начинают заниматься систематизацией данных о перемещениях абонентов с целью получить статистические данные о том, как люди на самом деле перемещаются в реальности.

Компания Verizon Wireless, крупнейший в США мобильный оператор с более чем 98 млн абонентов, в конце 2011 года изменила свою политику конфиденциальности так, что теперь она может передавать анонимные и агрегированные данные об абонентах третьим сторонам. Это сделало возможным в октябре прошлого года запуск специализированной программы - естественного продолжения того, что уже происходит в Интернете с веб-сайтами отслеживания кликов - с целью получить подробный анализ того, где посетители перемещаются и что их может заинтересовать. Кроме того, Verizon работает над тем, чтобы продавать демографические данные о людях, которые, например, принимают участие в каком-либо мероприятии, как они туда попали или какие виды приложений они используют, когда туда приходят.

Другие телекоммуникационные компании тоже изучают подобные идеи. В Европе, например, компания Telefonica запустила аналогичную программу в октябре 2014 года. «Пока это не кажется большой частью телекомбизнеса, однако такое может произойти», - говорит Vincent Blondel, прикладной математик, который работает над исследованием данной проблемы для мобильного оператора Orange. Он изучает данные объемом 2 млрд записей, полученных от 5 млн абонентов этого оператора в Африке.

Уже сейчас некоторые стартапы строят свой бизнес в этом направлении, агрегируя такого рода информацию из разных источников, поскольку отдельные компании, пусть даже и сотовые, такого предложить не могут. Например, компания AirSage в Атланте потратила почти десять лет, добиваясь эксклюзивных прав установить свое оборудование у двух из трёх самых больших операторов США с тем, чтобы собирать, анонимизировать, шифровать и анализировать данные сигнализации сотовых баз в реальном времени. Около года назад компания подписала свое второе соглашение о партнерстве (не уточняя, о каком операторе конкретно 
идет речь) и теперь, обрабатывая 15 млрд отметок о местонахождении каждый день, может просчитать движение около трети населения США с точностью до 100 м. Так как абонентские мобильные устройства периодически отмечаются на базах в разных местах, алгоритмы, разработанные в компании, смотрят на паттерны в таких местах главным образом для планирования потоков транспорта и мониторинга автомобильного движения.

Компания Streetlight Data как покупает данные от сотовых баз, так и использует данные GPS, которые могут быть применены для маркетинговых исследований (данные от сотовых сетей охватывают большое количество людей, но данные от GPS, собранные с помощью программных сервисов, позволяют улучшить точность). Программное обеспечение от Streetlight Data интерактивно, имеет цветную кодировку карт окрестностей и дорог и предоставляет больше практической информации. Она позволяет связать демографические данные людей, живущих рядом и пользующихся маршрутом постоянно, и отличить их от однократного посещения.

Спроецировав данный опыт [9] на рассматриваемые в настоящей статье аспекты исследуемой проблемы, можно сделать выводы относительно того, каким образом эта проблема решается за рубежом.

Организационные вопросы решаются путем привлечения к исследованию непосредственно операторов связи или создания стартапов (специализированных компаний), изучающих подвижность населения и разрабатывающих для этого программный продукт.

Юридическая возможность передачи информации об абонентах обеспечивается путем установления соответствующей корпоративной политики конфиденциальности так, что оператор связи может передавать анонимные и агрегированные данные об абонентах третьим лицам.

Техническая возможность собирать, анонимизировать, шифровать и анализировать данные сигнализации сотовых баз в реальном времени достигается путем размещения у операторов связи соответствующего специализированного оборудования.

Статистические возможности таких систем мониторинга практически неограниченны, так как позволяют обрабатывать десятки миллиардов отметок о местонахождении людей, что эквивалентно контролю за двумя третями населения страны в реальном масштабе времени.

Экономический аспект является движущей силой, стимулирующей движение операторов связи в направлении изучения и систематизации информации о перемещениях людей и видящей в ее сбыте новые источники доходов.

\section{Заключение}

Разработка рассмотренного научно-технического направления специалистами Сибирского федерального университета позволит создать эффективные методику, технологию и программный комплекс для изучения подвижности населения в мегаполисе, а в перспективе и постоянно действующий Центр мониторинга подвижности населения, что, в свою очередь, оптимизирует развитие улично-дорожной и маршрутной сети пассажирского транспорта на территориях г. Красноярска и Красноярского края в преддверии и в период проведения важнейшего международного события ближайшего пятилетия - Всемирной зимней универсиады 2019 года. 
Igor M. Blyankinshtein, Alexander I. Fadeev... Justification of Expediency of Studying Transport Mobility...

\begin{abstract}
Статья 63. Тайна связи.
1. На территории Российской Федерации гарантируется тайна переписки, телефонных переговоров, почтовых отправлений, телеграфных и иных сообщений, передаваемых по сетям электросвязи и сетям почтовой связи.

2. Операторы связи обязаны обеспечить соблюдение тайны связи.

3. Осмотр почтовых отправлений лицами, не являющимися уполномоченными работниками оператора связи, вскрытие почтовых отправлений, осмотр вложений, ознакомление с информацией и документальной корреспонденцией, передаваемыми по сетям электросвязи и сетям почтовой связи, осуществляются только на
\end{abstract} основании решения суда, за исключением случаев, установленных федеральными законами.

Статья 64. Обязанности операторов связи и ограничение прав пользователей услугами связи при проведении оперативно-розыскных мероприятий, мероприятий по обеспечению безопасности Российской Федерации и осуществлении следственных действий.

1. Операторы связи обязаны предоставлять уполномоченным государственным органам, осуществляющим оперативно-розыскную деятельность или обеспечение безопасности Российской Федерации, информацию о пользователях услугами связи и об оказанных им услугах связи, а также иную информацию, необходимую для выполнения возложенных на эти органы задач, в случаях, установленных федеральными законами.

2 Статья 7. Конфиденциальность персональных данных.

Операторы и иные лица, получившие доступ к персональным данным, обязаны не раскрывать третьим лицам и не распространять персональные данные без согласия субъекта персональных данных, если иное не предусмотрено федеральным законом.

3 Статья 6. Условия обработки персональных данных.

1.Обработкаперсональных данных должна осуществляться с соблюдениемпринципов иправил, предусмотренных настоящим Федеральным законом. Обработка персональных данных допускается в следующих случаях:

1) обработка персональных данных осуществляется с согласия субъекта персональных данных на обработку его персональных данных;

4) обработка персональных данных необходима для исполнения полномочий федеральных органов исполнительной власти, органов государственных внебюджетных фондов, исполнительных органов государственной власти субъектов Российской Федерации, органов местного самоуправления...;

8) обработка персональных данных необходима для осуществления профессиональной деятельности журналиста и (или) законной деятельности средства массовой информации либо научной, литературной или иной творческой деятельности при условии, что при этом не нарушаются права и законные интересы субъекта персональных данных;

9) обработка персональных данных осуществляется в статистических или иных исследовательских целях, за исключением целей, указанных в статье 15 настоящего Федерального закона, при условии обязательного обезличивания персональных данных.

4 Согласно Транспортной стратегии Российской Федерации на период до 2030 года, утвержденной распоряжением Правительства Российской Федерации от 22 ноября 2008 г. № 1734-р, в крупных городских агломерациях должны быть созданы центры территориально-транспортного планирования, одной из основных задач которых должна стать задача создания системы регулярных транспортных обследований для сбора надежных и представительных данных по ключевым показателям, необходимым для стратегического транспортного планирования по направлению транспортная подвижность населения с распределением на поездки общественным транспортом и поездки на легковых автомобилях.

5 «О федеральной службе безопасности»: федер. закон № 40-ФЗ от 3 апреля 1995 г. (в ред. от 22 декабря 2014 г.) Статья 12. Обязанности органов федеральной службы безопасности.

о) в обязанности органов федеральной службы безопасности входит участие в пределах своих полномочий совместно с другими государственными органами в обеспечении безопасности проводимых на территории Российской Федерации общественно-политических, религиозных и иных массовых мероприятий.

Статья 13. Права органов федеральной службы безопасности.

м) органы федеральной службы безопасности имеют право получать на безвозмездной основе от государственных органов, предприятий, учреждений и организаций независимо от форм собственности информацию, необходимую для выполнения возложенных на органы федеральной службы безопасности обязанностей, за исключением случаев, когда федеральными законами установлен запрет на передачу такой информации органам федеральной службы безопасности.

\title{
Список литературы
}

[1] Лебедева О.А. Дис. ... канд. техн. наук. Иркутск, 2014. 171 с.

[2] Аземша С.А. Разработка предложений по совершенствованию методов обследования пассажиропотоков и изучения корреспонденций пассажиров [Электронный ресурс]. - Режим доступа: www.rusnauka.com/18_DNI_2011/Tecnic/4_88562.doc.htm

[3] Хабаров В.И., Молодияов Д.О., Хомяков С.Г. // Доклады ТУСУР. № 1 (25). Ч.1. Томск, 2012. C. 113-117. 
[4] МТС Поиск. Услуга Локатор [Электронный ресурс]. - Режим доступа: https://www. mpoisk.ru/maps/locator/

[5] Мегафон-навигация. Услуга Радар [Электронный ресурс]. - Режим доступа: http:// moscow.megafon.ru/services/searchandnavi/sledi.html

[6] «О связи»: Ф3 № 126-Ф3 от 07.07.2003 (ред. от 21.07.2014).

[7] «О персональных данных»: Ф3 № 152-Ф3 от 27.07.2006 (ред. от 21.07.2014)

[8] Официальный сайт Территориального органа Федеральной службы государственной статистики по Красноярскому краю [Электронный ресурc]. - Режим доступа: http://www. gks.ru/dbscripts/munst/munst04/DBInet.cgi\#1

[9] Как мобильные операторы монетизируют данные о ваших перемещениях [Электронный ресурс]. - Режим доступа: http: //geektimes.ru/post/244338/

[10] Зедгенизов А.В., Лагерев Р.Ю., Левашев А.Г. // Социально-экономические проблемы развития и функционирования транспортных систем городов и зон их влияния: Материалы XVII Междунар. (20-й екатеринбургской) науч.-практ. конф. Екатеринбург, 2011. С. 90-97. 